\title{
Changes in the Microflora of Serra Cheese: Evolution Throughout Ripening Time, Lactation Period and Axial Location
}

\author{
Angela C. Macedo, M. Luz Costa \& F. Xavier Malcata ${ }^{a}$ \\ Escola Superior de Biotecnologia, Universidade Católica Portuguesa, Rua Dr António \\ Bernardino de Almeida, 4200 Porto, Portugal
}

\begin{abstract}
Changes in the microflora and physicochemical characteristics in Serra da Estrela cheese were examined using a three-way factorial design over a 35 day ripening period, throughout the lactation period, and for several slices taken normal to the cheese axis. Lactic acid bacteria were the major components of the microflora during ripening throughout the lactation period, but no statistically significant differences were detected between the surface and the interior of the cheese. Both enterobacteriaceae and staphylococri in the curd were at maximum numbers during the first week and were still at significant numbers towards the end of the maturation period. The numbers of staphylococci were statistically different between slices and at different times within the lactation period, whereas the numbers of enterobacteriaceae showed statistically significant variations only throughout the lactation period. Ripening time, lactation period and axial location significantly affected the number of yeasts. All factors studied had statistically significant effects on $p H$, salt and moisture content; the hypotheses that ripening time, lactation period, and axial location had effects on salt and moisture contents were accepted, in this order, at increasingly lower levels of significance; the hypotheses that ripening time, axial location, and lactation period had effects on $\mathrm{pH}$ were accepted, in this order, at increasingly lower levels of significance.
\end{abstract}

${ }^{a}$ To whom all correspondence should be addressed. 


\section{INTRODUCTION}

A unique flavour and texture have made Serra cheese the best of the traditional varieties of cheese produced in Portugal. Serra cheese is manufactured manually from October to May (the typical lactation period of Serra da Estrela ewes) from raw milk coagulated by a crude aqueous extract of dried flowers of cardoon (Cynara cardunculus L.) without a deliberately added starter culture. The coagulation temperature (ca. $30^{\circ} \mathrm{C}$ ) is kept approximately constant by placing the cheese vat by a fireplace and is evaluated empirically by the cheesemaker's finger tips, and coagulation time (ca. $2 \mathrm{~h}$ ) is empirically determined by visual assessment of the consistency of the coagulum, by observing the rheological behaviour upon shaking the cheese vat. The coagulum is "cut" by stirring with the bare hand. The irregularly-shaped curd pieces are poured into perforated, adjustable-diameter metal moulds, and the paste is pressed manually to assist in the expulsion of whey. Pressing, whenever employed, consists of placing a 6-20 kg flat stone on top of the fresh cheese in the mould for 3-24 h. Salt is rubbed on the top and bottom surfaces, and the cheeses are then placed in the maturation room, which is usually located next to the manufacture room and has no temperature or humidity control, although the external weather conditions prevailing in the Serra da Estrela mountains give a mean temperature of $10^{\circ} \mathrm{C}$ and a mean relative humidity of $90 \%$ during most of the ripening period. The cheeses are stored on wooden shelves, previously covered with a clean cotton cloth. The ripening period ranges from 30 to 45 days and the cheeses are inverted daily and washed with warm water once a week. At the end of ripening, Serra cheeses have a flat cylindrical shape, a diameter of $15-20 \mathrm{~cm}$, and a weight of $1-1.7 \mathrm{~kg}$; the rind is typically thin, uniform, smooth and straw yellow; the cheese has no eyes, its colour ranges from ivory to white, and it exhibits a buttery texture, strong aroma, and a clean, smooth and slightly acid flavour.

Technology, chemistry and microbiology of Serra cheese together with the plant coagulant used in its manufacture have been the subject of some studies which have been comprehensively reviewed by Macedo et al. (1993). Studies by Cruz (1945), Santos (1957) and Antunes \& Santos (1943) encompassing changes in the microbial profile during maturation and location within the cheese indicated that cocci predominate in the central and middle zones of the cheese, while yeasts tend to concentrate on the rind. Furthermore, the numbers of both cocci and rods tended to increase with time both in the interior and on the surface of the cheese, although the numbers of yeasts tended to decrease in the interior and to increase on the surface of the cheese. Some bacterial, yeasty and fungal flora of Serra cheese have been identified and classified by Hiscox et al. (1941), Antunes \& Santos (1943), Cruz (1945) and Santos (1957).

This communication reports the principal results of a study focussed on the numbers of viable cells belonging to the major groups of microorganisms usually found in cheese throughout the cheese ripening period, the axial location within the cheese and the lactation period. The salt, $\mathrm{pH}$ and moisture content of the cheeses were also measured because they are related directly to the microbial ecology prevailing in cheese. The objective of the present study was to provide further scientific insight into the ripening process, which is an essential condition for understanding the fundamentals of ripening, improving farmhouse procedures and establishing quality standards for the manufacture of Serra cheese. 


\section{MATERIALS AND METHODS}

\section{Manufacture and sampling}

The cheeses were manufactured according to the traditional cheesemaking practice (Macedo et al., 1993) at a selected, certified farmhouse located in Celorico da Beira (one of the regions of the Appelation d'Origine Controllee region of Serra cheese) in three sequential, duplicated batches of four $0.5 \mathrm{~kg}$ cheeses (1 week interval between replicates, for a total of eight cheeses manufactured); the first batch was made in late October and its duplicate in early November, the second batch in late January and its duplicate in early February, and the third batch in late May and its duplicate in early June. (The selection of a single farmhouse was the result of a thorough screening of several certified farmhouses in the Serra region; the farmhouse selected was the one that provided the best compromise of reliability over time, reasonable quality standards, willingness to participate in research studies and acceptable education level of the workers.) On the day of manufacture, a sample of $200 \mathrm{~mL}$ of milk was transferred directly from the milk collection vessel to a sterile Stomacher bag (Seward Medical, UK) and sent to our laboratory under refrigerated conditions (ca. $4^{\circ} \mathrm{C}$ ). On the same day and after 7 , 21 and 35 days, two of the eight cheeses made, wrapped in the cloth previously used to cover the wood shelf, were sent to our laboratory under refrigerated conditions. (Since the regular ripening time of Serra cheese prior to tentatively safe consumption ranges from 30 to 45 days, the maximum time span of ripening was, for the sake of minimization of trips between the dairy farm and our laboratory, taken as 5 weeks). Each cylindrically-shaped cheese was then divided into 12 slices (ca. $5 \mathrm{~mm}$ thick) in the axial direction starting from the rind towards the centre, and each set of two slices symetrically located within the cheese relative to the centre were put together and mixed using a sterile Stomacher bag, in order to obtain six final samples for analysis. Sterile knives and spatulas were used to handle and cut each cheese into slices, and all operations were performed in the vicinity of a Bunsen burner. Microbiological analyses were performed immediately upon receipt of the cheeses. The samples for chemical analyses were held at $-20^{\circ} \mathrm{C}$ for up to 40 days in appropriate vacuum packages.

\section{Microbiological analyses}

Cheese samples $(10 \mathrm{~g}$ ) were homogenized in $90 \mathrm{~mL}$ of a sterile solution of $2 \%$ (wt/ vol.) sodium citrate (Merck, Germany) at $45^{\circ} \mathrm{C}$ for $3 \mathrm{~min}$ in a Stomacher LabBlender 400 (Seward Medical, UK). Milk aliquots $(10 \mathrm{~mL})$ and cheese homogenates were diluted with sterile $0.1 \%$ peptone water (Sigma Chemical, St Louis, MO, USA), and plated in duplicate on a variety of media. Total aerobic viable counts in the cheese were obtained by plate count agar (PCA, Lab M, UK) using aerobic incubation at $30^{\circ} \mathrm{C}$ for 3 days. Mesophilic lactic acid bacteria were enumerated via plating samples on M17 agar (Lab M, UK) and Rogosa agar (RA, Oxoid, UK) using anaerobic incubation (Gas-Pak anaerobic system BBl, Cockeysville, MD, USA) at $30^{\circ} \mathrm{C}$ for 3 and 5 days, respectively. Coliforms were grown on violet red bile agar (VRBA, Lab M, UK) under aerobic incubation at $37^{\circ} \mathrm{C}$ for $24 \mathrm{~h}$. Staphylococci were determined on Baird-Parker medium (BPM, Lab M, UK) supplemented with egg yolk-tellurite (Lab M, UK) (Broeke, 1976) 
and incubated aerobically at $37^{\circ} \mathrm{C}$ for 2 days. Yeasts and moulds were enumerated on potato dextrose agar (PDA, Lab M, UK), acidified with sterile $10 \%$ lactic acid solution (Merck, Germany) and incubated aerobically at $25^{\circ} \mathrm{C}$ for $5 \mathrm{~d}$. Cycloheximide (100 $\mathrm{mg} \mathrm{L}^{-1}$ ) (Sigma, St Louis, MO, USA) was added to the M17A and RA to prevent growth of yeasts (Klander \& Weiss, 1986). The spreadplate technique was used for all media except VRBA, for which the pour-plate technique was used. Results were expressed as colony forming units (cfu) per $\mathrm{mL}$ for milk and cfu $\mathrm{g}^{-1}$ for cheeses.

\section{Chemical analyses}

Chemical analyses were conducted according to the methods described by Case et al. (1985). The $\mathrm{pH}$ was determined using a MicropH 2001 (Crison, Spain). Moisture and $\mathrm{NaCl}$ contents of the cheese samples were determined by the atmospheric oven method at $100^{\circ} \mathrm{C}$ for $24 \mathrm{~h}$ (EHRET, Germany) and the modified Volhard method, respectively, using reagents supplied by Merck (Germany).

\section{Experimental design}

Three time periods within the lactation season were considered (OctoberNovember, January-February and May-June), four points within the ripening period $(0,7,21$ and 35 days), and six axial positions within the cheese, thus forming a $3 \times 4 \times 6$ full factorial design (Box et al., 1978). The factorial experimental design was replicated twice since two independent batches of cheese were manufactured per period of the lactation season.

\section{Statistical analyses}

The use of statistical analysis based on the ANOVA table is valid if the experimental errors are independent and normally distributed, and if variance is constant. However, after using the original data in the construction of the ANOVA tables, preliminary analyses indicated that both the plot of the residuals versus the average of each set of two replicates (not shown) and the plot of residuals versus the percentiles of a normal distribution (not shown) were not consistent with the aforementioned assumptions but produced rather pronounced funnel-shaped and sigmoidal tendencies, respectively, for every variable measured (except $\mathrm{pH}$ and $\% \mathrm{NaCl}$ ). Therefore, the data had to be mathematically transformed to stabilize the variance and normalize the residuals before application of the ANOVA methodology would be statistically acceptable (Box et al., 1978). The transformed data had the form $\frac{y^{\lambda}-1}{\lambda \dot{y}^{1} \lambda}$ (where $\dot{y}$ is the geometric mean of all data $y$ in question), and the value of parameter, $\lambda$, was determined for each set of measurements by the likelihood estimation method, i.e. the value of $\lambda$ selected was the value for which the residual sum of squares of the transformed replicates with respect to their average is minimized (Box et al., 1978). To fully understand the experimental information generated, those data associated with significant factors were transformed back to the original form prior to plotting in Figs 1-9. 


\section{RESULTS AND DISCUSSION}

Changes in the major groups of microorganisms and the changes in $\mathrm{pH}, \mathrm{NaCl}$ $(\%)$, and moisture $(\%)$ involved in the ripening of Serra cheese versus the effects (ripening time and/or period within the lactation season and/or axial location within the cheese), which were significant at the $5 \%$ level (see Tables 1 and 2 ), are shown in Figs 1-6 and in Figs 7-9, respectively. Fach datum point represents the average of the duplicated cheesemaking trials.

The second order interaction between ripening time and lactation period $(T \times P)$ was statistically significant for the enumerations of microorganisms (see Table 1) and for $\mathrm{pH}$, salt (\%) and moisture (\%) (see Table 2). This interaction probably arises from the fact that the ripening time and the period within the lactation season are both time variables, and so are correlated with one another in view of their overlap.

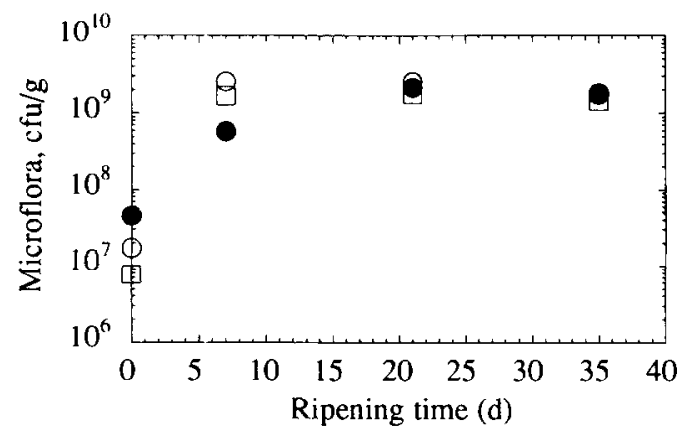

Fig. 1. Changes in numbers (average of two replicates) of total viable microorganisms, enumerated on plate count agar, during the ripening of Serra cheese produced in: OctoberNovember (O), January-February (O), and May-June ( $\square$ ). Microflora count for raw milk was $(7.55 \pm 3.62) \times 10^{5} \mathrm{cfu} \mathrm{mL}^{-1}$.

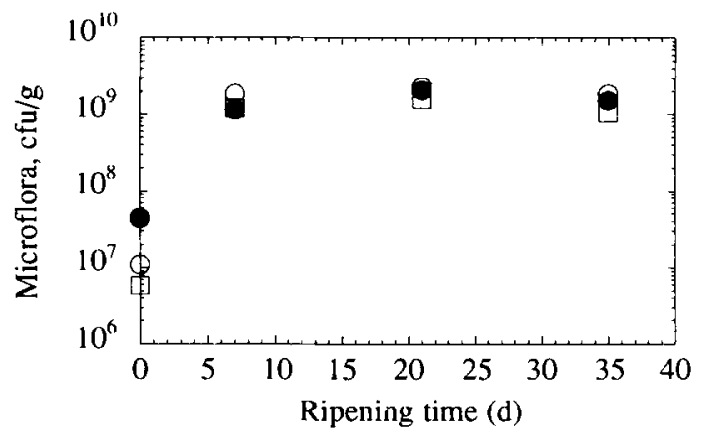

Fig. 2. Changes in numbers (average of two replicates) of lactic acid bacteria, enumerated on M17 agar, during the ripening of Serra cheese produced in: October-November $(O)$, January-February (O), and May-June ( $\square$ ). Microflora count for raw milk was $(1.10 \pm 0.13) \times 10^{6} \mathrm{cfu} \mathrm{mL}^{-1}$. 


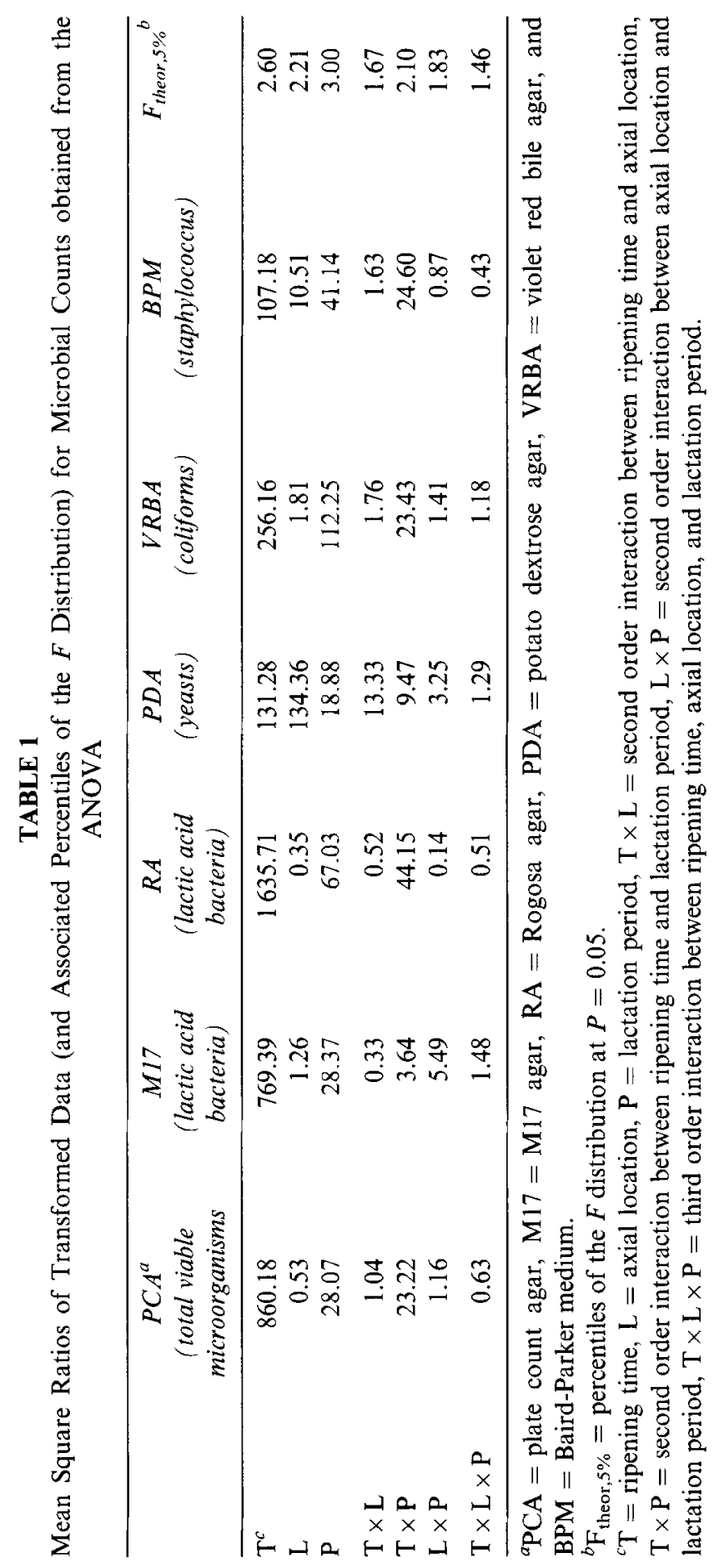


TABLE 2

Mean Square Ratios of Transformed Data (and Associated Percentiles of the $F$ Distribution) for Physicochemical Characteristics obtained from the ANOVA

\begin{tabular}{lrrrr}
\hline & \multicolumn{1}{c}{$p H$} & $\mathrm{NaCl}, \%$ & Moisture, $\%$ & $F_{\text {theor } 5 \%}{ }^{a}{ }^{a}$ \\
\hline $\mathrm{T}^{h}$ & 566.46 & 290.27 & 269.67 & 2.60 \\
$\mathrm{~L}$ & 37.53 & 10.06 & 7.97 & 2.21 \\
$\mathrm{P}$ & 21.52 & 91.99 & 93.55 & 3.00 \\
$\mathrm{~T} \times \mathrm{L}$ & 5.27 & 28.50 & 4.25 & 1.67 \\
$\mathrm{~T} \times \mathrm{P}$ & 6.14 & 20.51 & 20.70 & 2.10 \\
$\mathrm{~L} \times \mathrm{P}$ & 1.88 & 0.70 & 1.40 & 1.83 \\
$\mathrm{~T} \times \mathrm{L} \times \mathrm{P}$ & 0.63 & 0.37 & 0.84 & 1.46 \\
\hline
\end{tabular}

${ }^{a} \mathrm{~F}_{\text {theor.5\% }}=$ percentiles of the $F$ distribution at $P=0.05$.

${ }^{b} \mathrm{~T}=$ ripening time, $\mathrm{L}=$ axial location, $\mathrm{P}=$ lactation period, $\mathrm{T} \times \mathrm{L}=$ second ordere interaction between ripening time and axial location, $\mathrm{T} \times \mathrm{P}=$ second order interaction between ripening time and lactation period, $\mathrm{L} \times \mathrm{P}=$ second order interaction between axial location and lactation period, $\mathrm{T} \times \mathrm{L} \times \mathrm{P}=$ third order interaction between ripening time, axial location, and lactation period.

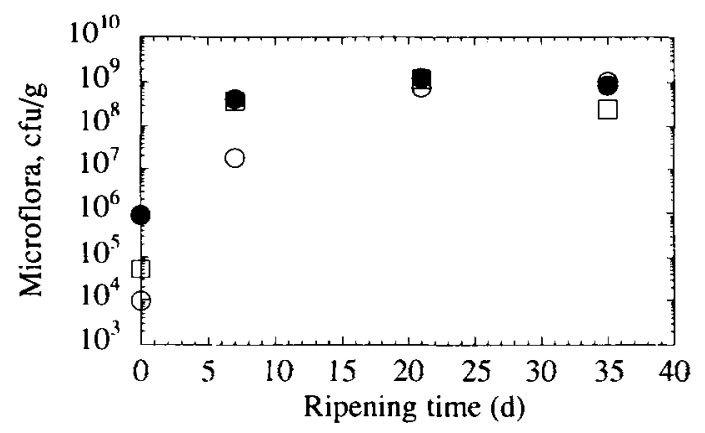

Fig. 3. Changes in numbers (average of two replicates) of lactic acid bacteria, enumerated on Rogosa agar, during the ripening of Serra cheese produced in: October-November $(O)$, January-February (O), and May-June ( $\square$ ). Microflora count for raw milk was $(9.08 \pm 2.12) \times 10^{6} \mathrm{cfu} \mathrm{mL}^{-1}$.

The second order interaction between ripening time and axial location $(\mathrm{T} \times \mathrm{L})$ was statistically significant at the $5 \%$ level for yeast and coliform counts (see Table 1), pH, and salt and moisture contents (see Table 2). One possible reason for this observation derives from the fact that such species as $\mathrm{H}^{+}, \mathrm{Na}^{+}$and $\mathrm{Cl}^{-}$, water and molecular oxygen are transported through the cheese essentially by molecular diffusion at a ratc that dircetly depends on the actual concentration gradients of those species at each axial position. Since Fick's second law (which mathematically describes these phenomena) is highly nonlinear on both spatial position and time, it is expected that $\mathrm{pH}$, salt content and moisture content (and also molecular oxygen), as well as the numbers of microorganisms which depend 

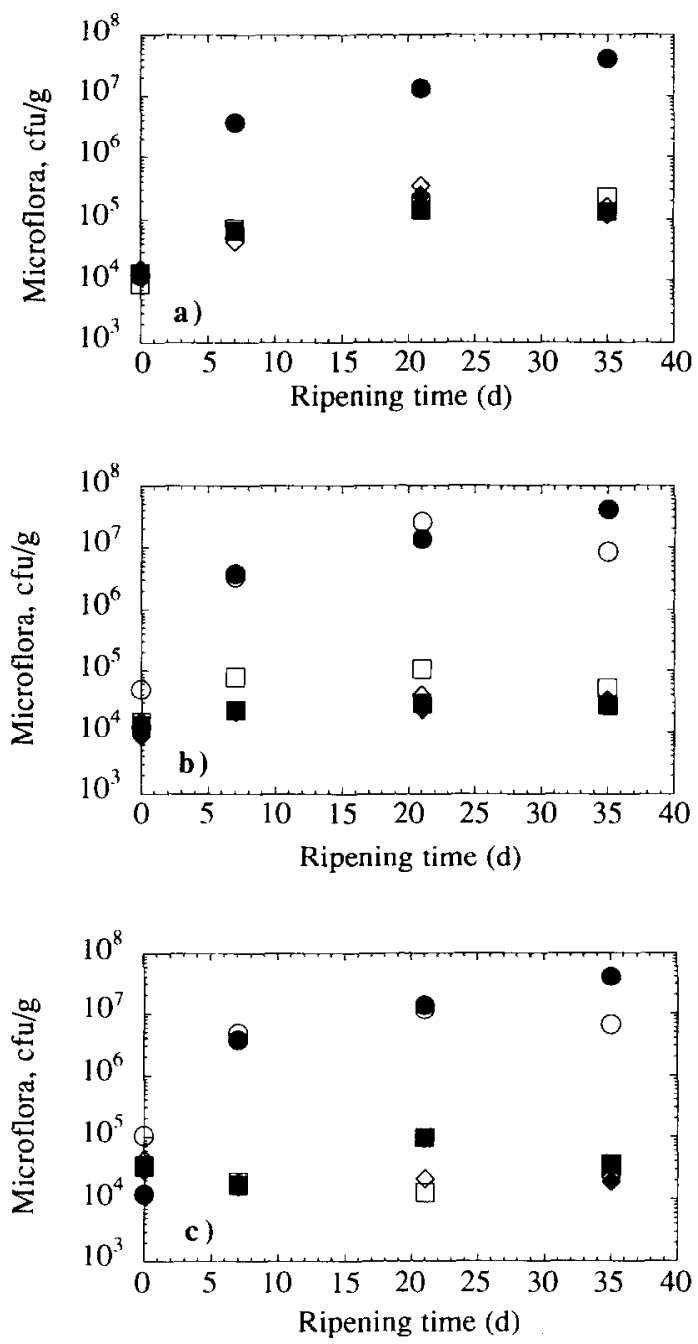

Fig. 4. Changes in numbers (average of two replicates) of yeasts, enumerated on potato dextrose agar, during the ripening of Serra cheese produced in: (a) October-November, (b) January-February, and (c) May-June. Slices: 1 (rind, $\bigcirc), 2(0), 3(\square), 4(\square), 5(0)$, and 6 (center of the cheese, $\diamond$ ). Microflora count for raw milk was $(1.65 \pm 1.15) \times 10^{3} \mathrm{cfu} \mathrm{mL}^{-1}$.

strongly on these species for viability, do not depend on axial position and ripening time in a simple linear fashion.

The sccond order interaction between axial location and lactation period $(\mathrm{L} \times \mathrm{P})$ was significant at the 5\% level for lactic acid bacteria enumerated on M17 and yeasts (see Table 1), as well as for $\mathrm{pH}$ (see Table 2). It is reasonable to accept that this interaction arises from the mutual interactions discussed previously (i.e., $\mathrm{T} \times \mathrm{L}$ and $\mathrm{T} \times \mathrm{P}$ ). 


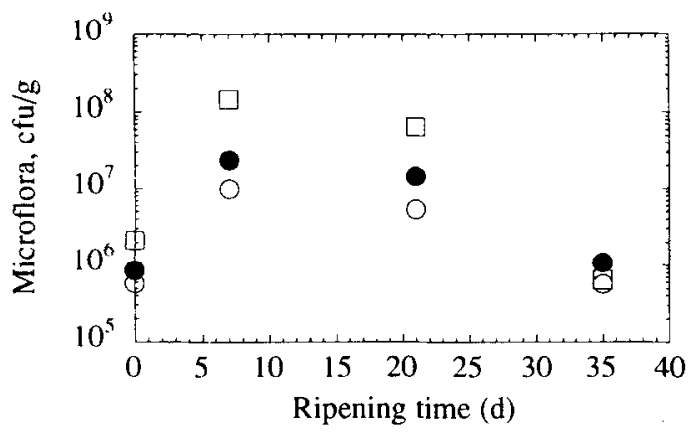

Fig. 5. Changes in numbers (average of two replicates) of coliforms, enumerated on violet red bile agar, during the ripening of Serra cheese produced in: October-November $(O)$, January-February ( $\odot$ ), and May-June $(\square)$. Microflora count for raw milk was $(2.52 \pm 2.95) \times 10^{5} \mathrm{cfu} \mathrm{mL}^{-1}$.

The third-order interaction between the factors studied $(\mathrm{T} \times \mathrm{L} \times \mathrm{P})$ was negligeable (see Tables 1 and 2) for all microbiological and physicochemical parameters measured. This result was anticipated because high order interactions are often of the order of magnitude of the intrinsic experimental variability (Box et al., 1978).

The high bacterial counts in the cheese samples can probably be attributed to post-milking contamination of ewes' milk. Total viable counts for raw ewes' milk exceeding $10^{6} \mathrm{cfu} \mathrm{mL}^{-1}$ have been reported (Bautista et al., 1986; Gonzalez de Llano et al., 1992; Nunez et al., 1984). The total viable counts (see Fig. 1) increased significantly during the 1 st week $(100$-fold $)$, then tended to level off at 21 days (ca. $2 \times 10^{9} \mathrm{cfu} \mathrm{g}^{-}$), and were followed by a slight decrease near 35 days.

\section{Lactic microflora}

Lactic microorganism enumerated on M17 (see Fig. 2) and RA (see Fig. 3) were the major components of the total microflora during ripening. Changes in M17 and RA lactic microflora were similar to those reported by other researchers for lactococci and lactobacilli in artisanal cheeses (Fontecha et al., 1990; Gonzalez de Llano et al., 1992; Marcos et al., 1986). Counts for microflora on M17 and RA increased 100- and 1000-fold, respectively, during the first week. For 21 day old cheese, the counts on M17 (ca. $2 \times 10^{9} \mathrm{cfu} \mathrm{g}^{-1}$ ) and RA (ca. $1 \times 10^{9} \mathrm{cfu} \mathrm{g}^{-1}$ ) were maximum; thereafter, both counts decreased slightly. Although lower numbers of lactic acid bacteria on the surface than in the interior have been reported for such related Spanish cheeses as Gamonedo and Serena (Fernandez del Pozo et al., 1988; Gonzalez de Llano et al., 1992), differences between slices (see Table 1) for total viable microflora, M17 microflora and RA microflora were not significant $\left(\begin{array}{ll}P & 0.05\end{array}\right)$. The lactation period had a significant effect, at the $5 \%$ level of significance, on the numbers of microorganisms in the cheese; the numbers of microorganisms tended to be highest for the January-February period and lowest for May-June. This result is partly due to the poor housing conditions in winter. 

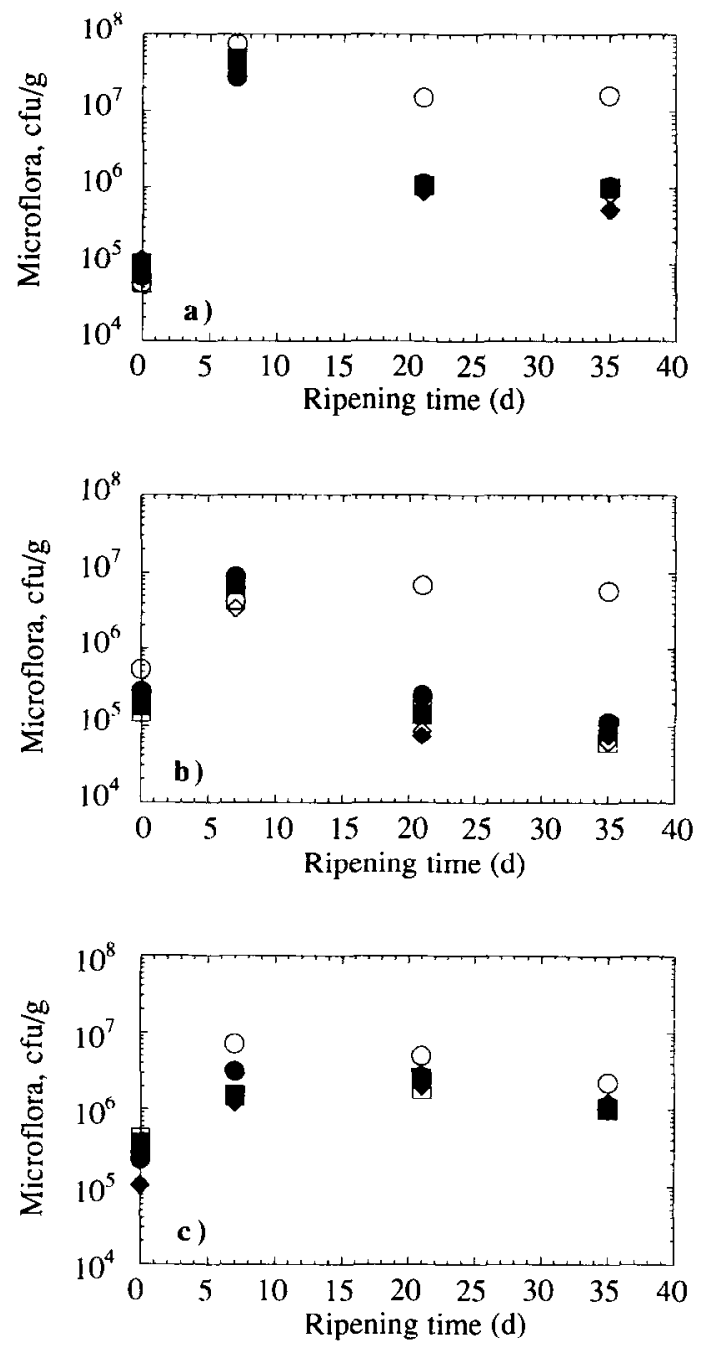

Fig. 6. Changes in numbers (average of two replicates) of staphylococcus, enumerated on Baird-Parker medium, during the ripening of Serra cheese produced in: (a) OctoberNovember, (b) January-February, and (c) May-June. Slices: 1 (rind, O), 2 (O), 3 ( $\square$ ), $4(\square), 5(\diamond)$, and 6 (center of the cheese, $\diamond$ ). Microflora count for raw milk was $(1.58 \pm 0.54) \times 10^{3} \mathrm{cfu} \mathrm{mL}^{-1}$.

\section{Yeasts and moulds}

Although some researchers (Arizcun et al., 1993; Marcos et al., 1986) found moulds in some artisanal cheeses made from raw milk (e.g., Idiazabal and Roncal cheeses made from ewes' milk and Cabrales cheese made from a mixture of cows' and ewes' milks), moulds were not found in our experiments in milk, curd or cheese. Ripening time, lactation period and axial location all significantly affected 

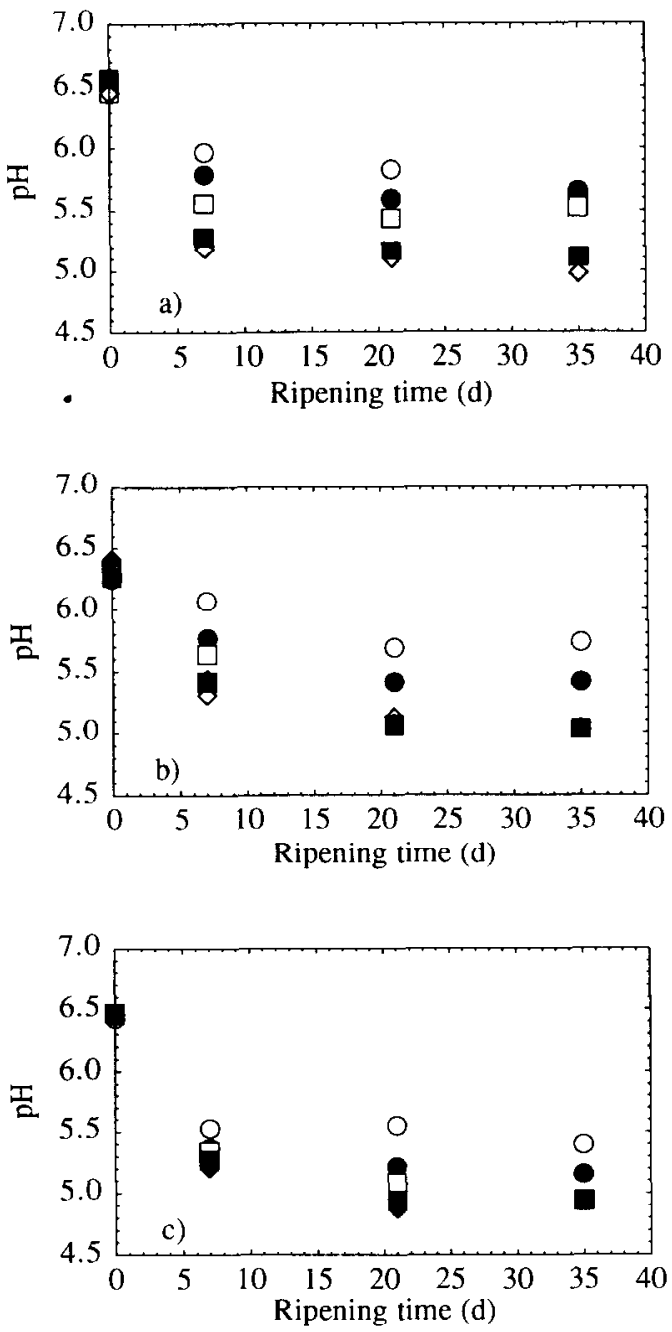

Fig. 7. Changes in the $\mathrm{pH}$ values (average of two replicates) during the ripening of Serra cheese produced in: (a) October-November, (b) January-February, and (c) May-June.

Slices: 1 (rind, 0$), 2(\bullet), 3(\square), 4(\square), 5(\diamond)$, and 6 (center of the cheese, $\bullet$ ).

the number of yeasts, or PDA microflora, at the 5\% level; however, the hypotheses that the axial location and the ripening time have significant effects on the numbers of yeasts are accepted at approximately the same and lower level of significance than the hypothesis that the lactation period has a significant effect (see Table 1). Microflora counts on PDA increased 10-fold in the interior of the cheese during the initial 21 day period, and tended to decrease slightly afterwards (see Fig. 4). This pattern can probably be accounted for by the low $\mathrm{pH}$, high moisture content, and the fact that some yeasts tend to be facultative anerobes. 

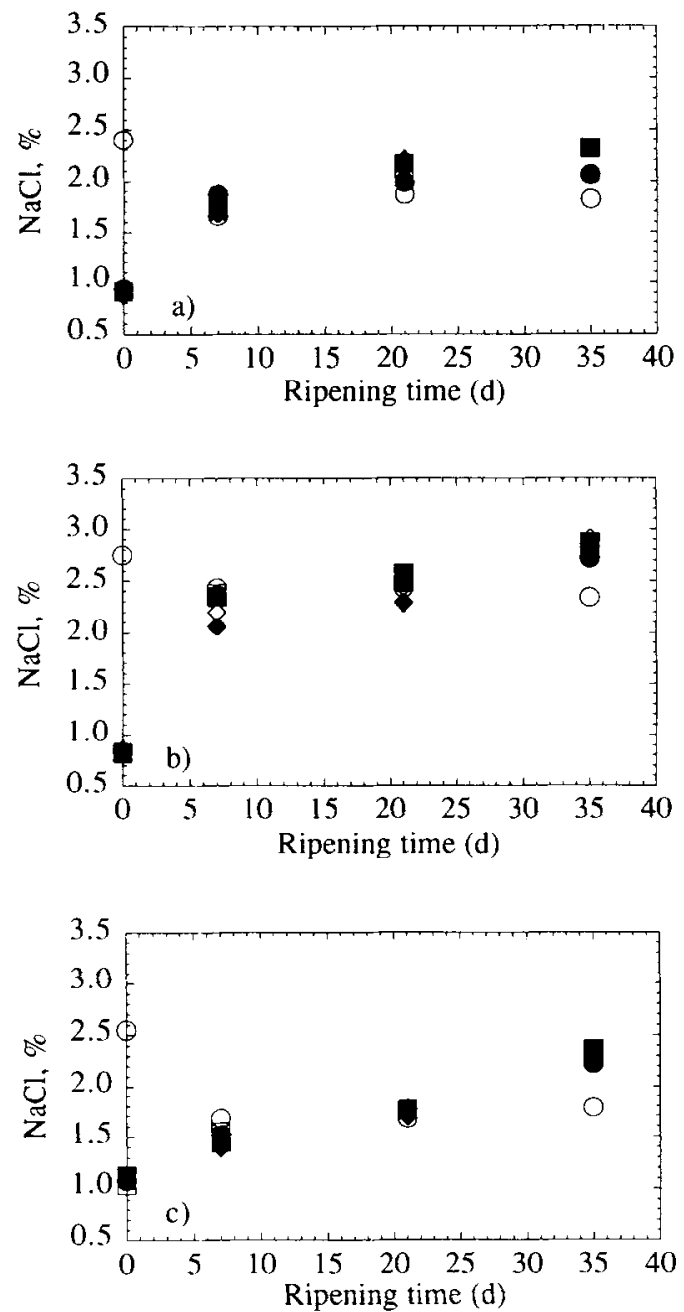

Fig. 8. Changes in the salt content values (average of two replicates) during the ripening of Serra cheese produced in: (a) October-November, (b) January-February, and (c) MayJune. Slices: 1 (rind, $\bigcirc), 2(\bullet), 3(\square), 4(\square), 5(\diamond)$, and 6 (center of the cheese, $\diamond$ ).

The higher values for PDA microflora for rind samples than for samples taken from the interior of the cheese (100-fold) was probably because the rind is easily contaminated from the environment, which is at a favourable temperature and relative humidity and is aerobic for such yeasts to grow.

\section{Enterobacteriaceae and staphylococci}

The generally poor microbial quality of Serra cheese is directly related to the high numbers of enterobacteriaceae and staphylococci found in raw milk, which 

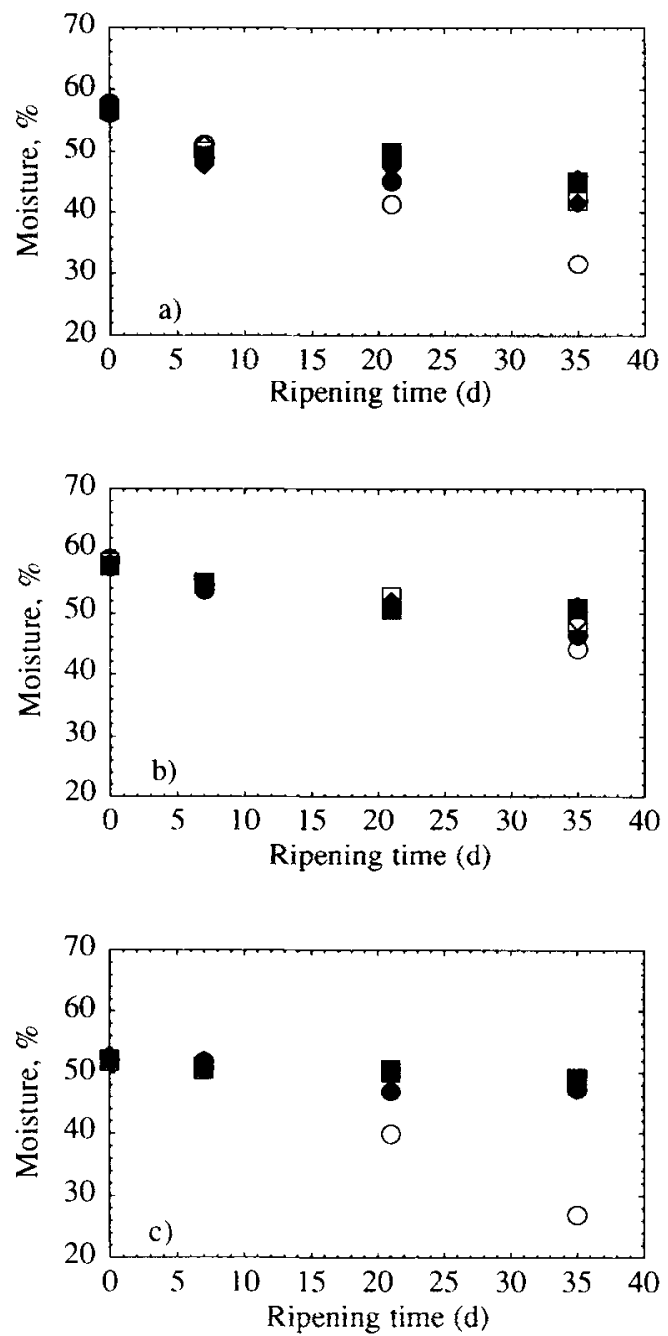

Fig. 9. Changes in moisture content values (average of two replicates) during the ripening of Serra cheese produced in: (a) October-November, (b) January-February, and (c) MayJune. Slices: 1 (rind, $\bigcirc$ ), $2(\bigcirc), 3(\square), 4(\square), 5,(\diamond)$, and 6 (eenter of the cheese, $\diamond$ ).

are an index of the poor sanitary conditions prevailing during milk production and collection. Enterobacteriaceae in raw ewes' milk range between $10^{2}$ and $10^{3}$ cfu $\mathrm{mL}^{-1}$ (Gaya et al., 1987). The microflora of raw milk enumerated on VRBA was quite variable (viz. 0 to $5.5 \times 10^{5} \mathrm{cfu} \mathrm{mL}^{-1}$ ), which agrees with the poor sanitary conditions of the milking process. The numbers of microorganisms enumerated on BPM were in agreement with those reported by Bautista et al. (1986) $\left(10^{3}\right.$ to $\left.10^{4} \mathrm{cft}_{\mathrm{mL}}^{-1}\right)$. Of all three factors considered, the level of significince for acceptance of ripening time as having a statistically significant effect 
on these bacterial counts was lowest (scc Table 1). Although counts on VRBA at 0 days were already quite high (ca. $10^{5} \mathrm{cfu} \mathrm{g}^{-1}$ ), they increased 10 -fold during the first week. Their numbers decreased to their original value after 35 days (see Fig. 5). Such a decrease in bacterial counts on both VRBA and BPM may be attributed to physicochemical conditions prevailing in the cheese (increase in the $\mathrm{NaCl}$ content and decrease in $\mathrm{pH}$ ) that are unfavourable for microbial growth. However, after 35 days, both types of microorganisms (VRBA and BPM) were still present (note that the moisture content never fell below $45 \%$ ). Bacteria enumerated on both VRBA and BPM in May-June were higher than during the other two periods because the growth of enterobacteriaceae and staphylococci is particularly favoured by the temperatures around $15^{\circ} \mathrm{C}$ which prevail during these months. Axial distance to the centre of the cheese also significantly influenced the numbers of microorganisms on BPM $(P<0.05)$. The rind had counts approximately two orders of magnitude greater than samples of cheese taken from the inside (see Fig. 6) for the same ripening time and position in the lactation period, although the counts for the rind did not decrease with ripening time as did those for the inner slices. Staphylococci require oxygen to survive and grow, and contamination of the rind is more likely because of the higher $\mathrm{pH}$ and the number of manual washing operations throughout maturation. The hypothesis that there are significant differences in counts between the rind and the interior of the cheese is accepted at a lower level of significance for the May-June period than for the other two periods, probably because the initial contamination and the ripening temperature were higher in May-June than in October-November and January-February. The numbers of microorganisms enumerated on VRBA and BPM in the early stages of ripening are in agreement with values reported in the literature (Bautista et al., 1986; Fontecha et al., 1990; Marcos et al., 1986).

\section{pH, salt and moisture contents}

The two time variables and the space variable studied all had significant effects on $\mathrm{pH}$, moisture content and salt content $(P<0.05)$; for salt and moisture contents, the hypotheses that ripening time, lactation period and axial location (in this order) have statistically significant effects were accepted at higher and higher levels of significance; for $\mathrm{pH}$, the order was ripening time, axial location and lactation period.

The decrease in $\mathrm{pH}$ during ripening (see Fig. 7) can be associated with the lactic fermentation by lactic acid bacteria, especially by the microflora grown on RA, because they multiplied faster than the microorganisms enumerated on M17 during the first week. A similar change in $\mathrm{pH}$ was reported for Majorero cheese by Fontecha et al. (1990), and the final pH of the cheeses were similar to those reported by Marcos et al. (1983) for Spanish cheeses made from raw ewes' milk. At any particular ripening time, the $\mathrm{pH}$ was lowest in JanuaryFebruary, probably due to the greater production of lactic acid by the higher numbers of microorganisms counted on $\mathrm{M} 17$ and RA during this period relative to the other two periods. Furthermore, our results indicate the existence of a $\mathrm{pH}$ profile in Serra cheese: although no significant differences in $\mathrm{pH}$ were found between the slices (as a whole) taken from the cheese, the average $\mathrm{pH}$ (ca. 5.0) of the inner four slices was clearly lower than that of the rind (ca. 5.8); 
a zone of $\mathrm{pH}$ transition (approximatcly corresponding to the second slice) exhibited an intermediate $\mathrm{pH}$ between 5.0 and 5.8. This observation may be explained by the significant yeast count on the rind, which use lactic acid as a carbon source.

The salt content increased considerably during the first week, although the maximum values were reached after 35 days (see Fig. 8). At this time, the salt content in the rind was statistically below that in the interior of the cheese $(P<0.05)$. This observation was expected considering that the surface of Serra cheese is cleaned periodically and washed during ripening at time intervals that are very close compared with the time scales associated with diffusion within cheese matrices. The variability in salt content between cheeses may be attributed to the empirical and, to a certain extent, random method of salt application on the surface by the cheesemaker. Marcos et al. (1983) showed that the water activity $\left(a_{w}\right)$ of soft cheeses (with a moisture content above $40 \%$ ) can be predicted from the molal concentration of salt in cheese water $\left(\mathrm{C}_{\mathrm{NaCl}}\right)$ by the simple correlation $\mathrm{a}_{\mathrm{w}}=1-0.033 \mathrm{C}_{\mathrm{NaCl}}$. If this relationship were valid in our case, the expected $\mathrm{a}_{\mathrm{w}}$ of Serra cheese would be in the order of 0.96 .

The hypothesis that the axial position has a statistically significant effect on the moisture content of the cheese was accepted at increasingly lower levels of significance towards the later periods of lactation. Lower moisture contents were found for the rind, as expected. The moisture content of the various slices at different stages of the lactation period is a direct function of the environmental ripening conditions: in Serra da Estrela mountains, environmental temperatures and relative humidities of $5{ }^{\circ} \mathrm{C}$ and $90 \%$, respectively, in January, and $15^{\circ} \mathrm{C}$ and $70 \%$ in May are quite common. The moisture content of the cheeses is thought to have decreased with aging due mainly to evaporation of water.

As emphasized by Macedo et al. (1993), extensive information on the microbial ecology throughout ripening of Serra cheese is essential prior to any attempt to standardize the production of this unique cheese. We hope that the microbiological and physicochemical data generated in this research work, although incomplete and crude, will serve as a starting point for detailed fundamental work towards the ultimate goal of selecting a specific starter for Serra cheese, a sine qua non condition for the successful standardization of its manufacture.

\section{ACKNOWLEDGEMENTS}

The authors are grateful to Dr Timothy A. Hogg (Escola Superior de Biolecnologia) and Prof. Edmund Zottola (University of Minnesota) for their availability to discuss some points of relevance to the reported research effort. The careful and critical reading by Prof. Patrick Fox (University College Cork) is hereby gratefully acknowledged. The authors are indebted to the members of the technical board of ANCOSE (the National Portuguese Breeders Association for Serra da Estrela Sheep) for their cooperation in supervising the local manufacture of the cheeses according to the design presented and in transporting the cheeses used in this study to the ESB premises. Financial support for A. C. Macedo was provided by a Ph.D. fellowship within the Program for the Creation of National Infrastructures in Applied Science and Investigation (CIENCIA) administered by 
the National Board for Scicntific and Tecnological Investigation (JNICT, Portugal). Financial support for M. L. Costa was provided by a fellowship within the Specific Program for the Development of the Portuguese Industry (PEDIP, Portugal).

\section{REFERENCES}

Antunes, T.M. \& Santos, I. (1943). Elementos para o estudo do queijo da Serra. Boletim Pecuário, 11, 101-56.

Arizcun, C., Itulain, M., Salmerón, J. \& Torre, P. (1993). Fungi study of ewe's raw milk cheese. In Food Control: On-Line Control for Improved Quality, European Federation of Food Science and Technology (EFFoST), 26-28 September. Porto, Portugal, 52-3.

Bautista, L., Bermejo, M.P. \& Nunez, M. (1986). Seasonal variation and characterization of Micrococcaceae present in raw ewes' milk. J. Dairy Res., 53, 1-5.

Box, G.E.P., Hunter, W.G. \& Hunter, J.S. (1978). Randomized blocks and two way factorial designs. In Statistics for Experimenters: an Introduction to Design, Data Analysis, and Model Building, Wiley, New York, pp. 208-44.

Broeke, R.T. (1976). The Staphylococcus medium of Baird-Parker in practical use. The occurence of coagulase-positive, egg-yolk non-clearing staphylococci. Antonie van Leeuwenhoek, 33, 22036.

Case, R.A., Bradley, R.L. Jr \& Williams R.R. (1985).Chemical and physical methods. In Standards Methods for the Examination of Dairy Products., ed., G.H. Richardson, American Public Health Association, Washington, DC, pp. 327-94.

Cruz, A.A. (1945). Lacticínios da Beira Baixa: queijo à ovelheira e queijo à cabreira. Boletim Pecuário, 12, 105-25.

Fernández del Pozo, B., Gaya, P., Medina, M., Rodriguez-Marín, M.A. \& Nunez, M. (1988). Changes in the microflora of La Serena cwc's milk checse during ripening. $J$. Dairy Res., 55, 449-55.

Fontecha, J., Peláez, C., Juárez, M., Requena, T. \& Gómez, C. (1990). Biochemical and microbiological characteristics of artisanal hard goat's cheese. J. Dairy Sci., 73, 11507.

Gaya, P., Medina, M. \& Nunez, M. (1987). Enterobacteriaceae, coliforms, faecal coliforms and salmonellas in raw ewe's milk. J. Appl. Bacteriol., 62, 321-6.

González de Llanu, D., Ramus, M., Rudriguez, A., Montilla, A. \& Juárez, M. (1992). Microbiological and physicochemical characteristics of Gamonedo Blue cheese during ripening. Int. Dairy J., 2, 121-35.

Hiscox, E.R., Rowland, J., Wolf, J. \& Jacob, M. (1941). Nota acerca da bacteriologia e química do queijo português de leite de ovelha (Serra). Boletim Pecuário, 9, 163-5.

Klander, O. \& Weiss, N. (1986). Genus Lactobacillus. In Bergey's Manual of Systematic Bacteriology, Williams and Wilkins, Baltimore, pp. 1209-19.

Macedo, A., Malcata, F.X. \& Oliveira, J.C. (1993). The technology, chemistry and microbiology of Serra cheese: a review. J. Dairy Sci., 76, 1725-39.

Marcos, A., Millan, R., Esteban, M.A., Alcalá, M. \& Fernandez-Salguero, J. (1983). Chemical composition and water activity of Spanish cheeses. J. Dairy Sci., 66, 2488-93.

Marcos, I., Quintana, M., Iñigo, B., Martin, D. \& Barneto, R. (1986). Estudio microbiológico del queso de Cabrales. I. Evolución de la flora. Alimentaria, 171, 65-7.

Nunez, J.A., Chavarri, F.J. \& Nunez, M. (1984). Psychrotrofic bacterial flora of raw ewe's milk with particular reference to Gramnegative rods. J. Appl. Bacteriol., 57, 23-9.

Santos, I.A. (1957). O queijo da Serra. Boletim Pecuário, 25, 5-83. 